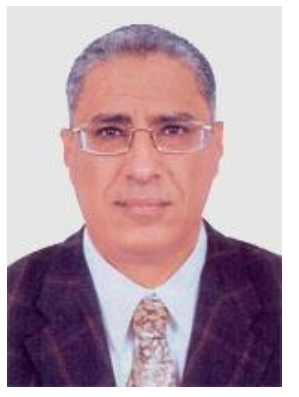

\title{
Sustainable Development is the only path to achieve the green economy
}

\author{
Eng. Ahmed Abou Elseoud
}

Sustainable development is the management of renewable resources for the good of the entire human and natural community. Built into this concept is an awareness of the animal and plant life of the surrounding environment .The goal of sustainable development is to provide resources for the use of present populations without compromising the availability of those resources for future generations, and without causing environmental damage that challenges the survival of natural ecosystems. Consequently, sustainable economies cannot be based on the use of non-renewable resources. Ultimately, sustainable economies must be supported by the use of renewable resources such as biological productivity, and solar, wind, geothermal, and biomass energy sources. However, even renewable resources may be subjected to overexploitation and other types of environmental degradation. Central to the notion of sustainable development is the requirement that renewable resources are utilized in ways that do not diminish their capacity for renewal, so that they will always be present to sustain future generations of humans. On the other hand, Egypt welcomes the concept of the green economy to achieve sustainable development ,within the framework of respect for national priorities of each country, in order to achieve more decent work opportunities, and developments continued, and use environmental resources. Egypt have passed already in the implementation of a number of pilot projects in this regard, and look forward to witnessing the next stage for more cooperation with development. The energy is the main driver of economic and social development with the necessity to development of primary energy resources and the proper management and use of the most important policies and development strategies Egypt depends in achieving economic development and technological several sources of energy available to a power and petroleum and natural gas, but that recently Egypt has seen a severe lack of energy due to the following reasons Increased energy consumption rate - Lower crude oil and gas production rates in the country Some electricity production plants with low efficiency - increasing proportion of commercial waste- Slow expansion of the use of alternative energy .In this sense the Ministry of Environment has searched for alternative sources of energy assessing its environmental impact and its economic and social impact at the same time and take measures and actions that would raise sustainable proportion of renewable energy in the Egyptian energy mix and working to reduce the pressures of climate change where can these measures can contribute to maximize the utilization of alternative energy resources and traditional such as the use of solid waste as well as alternative fuels and use them as a form of alternative energy.

\footnotetext{
About Eng. Ahmed Abou Elseoud

Currently the Chief Executive Officer, Egyptian Environmental Affairs Agency, Ministry of Environment. He has over 29 years of experience in different aspects and phases of water environmental management. He also has a significant expertise in computer modelling, management information systems, decision support systems and environmental quality monitoring and analysis including oversight of biomonitoring and environmental flow monitoring to EU Water Framework Directives, in Egypt, Armenia, Azerbaijan and Georgia. Eng Abou Elseoud has served as Water Resources Planner in the Egyptian Ministry of Water Resources and Irrigation for 15 years and moved to the Ministry of Environment where promoted to be the First Deputy Secretary Head of the Central Department for Environmental Quality in the Egyptian Ministry of Environment. He is a member of the Management Board of the Egyptian Electricity Holding Company, Cairo, charged with reviewing annual strategic planning, investment project and tariff structures for electricity in Egypt.
} 